\title{
THE WETTING BEHAVIOUR AND DISPERSION RATE OF COCOA POWDER IN WATER
}

\author{
L. GALET*, T. O. VU, D. OULAHNA and J. FAGES \\ Chemical Engineering Laboratory for Particulate Solids, CNRS UMR 2392, Ecole des Mines d'Albi-Carmaux, Albi cedex, France
}

\begin{abstract}
$\mathrm{T}$ he efficient dispersion of powders in liquids is required in many fields. However, there are only a few studies on the physicochemical properties of the powders and the dispersion rate. The process of dispersing an agglomerated powder is mainly controlled by the forces acting between the primary particles, and between particles and liquid. In this paper, we present an experimental study of the dispersion kinetics of a hydrophobic powder (cocoa) in water. We firstly determined the surface free energy of the powder using several methods (static wettability, dynamic wettability). Interpretation of calculated values of spreading coefficients and interaction parameters revealed no energetically favoured cocoa-water interactions. A series of dispersion experiments were conducted in a stirred vessel to investigate the influence of stirring speed, temperature and concentration of powder in water. The dispersion concentration was measured using an optical scattering method, which was shown to give good information for evaluating the dispersion process. The experimental data fit an exponential mathematical model with two parameters $(A, \alpha)$ : $X(t)=A[1-\exp (-\alpha t)]$. It was found that the rate of dispersion depends on the agitation speed with a critical speed $630 \mathrm{rpm}$. All results are discussed as a function of the agitation speed and temperature.
\end{abstract}

Keywords: wettability; cocoa powder; surface energy; dispersion; optical fibre sensor.

\section{INTRODUCTION}

Dispersion is defined as the uniform repartition of a solid in a liquid. To disperse a powder in a liquid is an important stage in various industrial processes and many actions in daily life. This includes successive or simultaneous steps such as wetting, sinking, dispersion and dissolving for soluble compounds (Schubert, 1993). Generally, agglomeration is used to improve the dispersion rate of a powder. The process of dispersing an agglomerated powder is mainly controlled by the forces acting between the primary particles and between particles and liquid, but only a few studies relate the physicochemical properties of the powders and the dispersion rate. In this paper, we present an experimental study of the dispersion kinetics of the free cocoa powder in water. The wetting behaviour of this agglomerated food powder in low-fat milk has recently been studied as a function of the amount of fine particles added in the prepared instant product (Kyaw Hla and Hogekamp, 1999). Unfortunately, no discussion of the liquid-solid interactions has been reported. For this purpose, we firstly determined the surface free energy of

*Correspondence to: Dr L. Galet, Chemical Engineering Laboratory for Particulate Solids, CNRS UMR 2392, Ecole des Mines d'AlbiCarmaux, Campus Jarland, 81013 Albi cedex 09, France.

E-mail: laurence.galet@enstimac.fr the pure cocoa powder using several methods. The dispersion kinetics of cocoa in water were investigated using an optical method, as a function of two physical parameters: agitation speed and temperature.

\section{MATERIALS AND METHODS}

\section{Main Physical Properties of Cocoa Powder}

The cocoa powder used in this study has been characterized in terms of particle size, flowability and various density measurements (Vu et al., 2003). The main characteristics are summarized in Table 1. The cocoa powder is a fine and very cohesive powder.

\section{Surface Free Energy and Contact Angle Measurements}

Several methods can be used to determine the surface energy of a powder. The first method is referred to as Stevens's method (Stevens et al., 1974). This method is qualitative and subjective. It consists of sprinkling the powder on the surface of solutions of known surface energy. The value of the powder surface energy is taken to be that of the surface energy of the mixture for which the sprinkled powder is wetted in less than $1 \mathrm{~min}$. Other methods are based on some static or dynamic contact 
Table 1. Physical properties of cocoa powder.

\begin{tabular}{ll}
\hline Mean particle size $(\mu \mathrm{m})$ & $D_{50}=16$ \\
Span: $\left(D_{90}-D_{10}\right) / D_{50}$ & 2.2 \\
True density $\left(\mathrm{g} \mathrm{cm}^{-3}\right)$ & $1.44 \pm 0.01$ \\
Aerated density $(D a)\left(\mathrm{g} \mathrm{cm}^{-3}\right)$ & $0.34 \pm 0.01$ \\
Packed density $(D p)\left(\mathrm{g} \mathrm{cm}^{-3}\right)$ & $0.67 \pm 0.01$ \\
Carr ratio $=(D p-D a) / D p$ & $49 \%$, very bad flowability \\
Hausner ratio $=D p / D a$ & 1.96, very cohesive \\
\hline
\end{tabular}

angle measurements, Young's sessile drop method and Washburn's capillary rise method. Those methods are well known and described in the literature (Buckton, 1990; Good, 1977; Yang et al., 1988). The sessile drop method consists of the deposition of a drop of liquid on a compressed powder disc or on the surface of the packed powder, and measuring the contact angle formed by the drop on the surface. The use of different liquids permits the estimation of the limiting surface energy of a liquid to wet the powder (Zisman, 1964). The capillary rise method consists of measuring the rates of penetration of two liquids into a powder bed, one of which is known to be perfectly wetting and is used to determine a 'constant parameter' and the other is the liquid for which a contact angle is required [see equation (1)]: $m=$ mass of liquid, $t=$ time, $K=$ constant parameter, $\rho=$ liquid density, $\gamma_{\mathrm{L}}=$ liquid surface energy, $\theta=$ contact angle, $\eta=$ liquid viscosity.

$$
\frac{m^{2}}{t}=\frac{K \rho^{2} \gamma_{\mathrm{L}} \cos \theta}{2 \eta}
$$

These three different methods were used to estimate the surface energy of cocoa powder. Stevens's method was used with solutions composed of mixtures in different proportions of water and 2-propanol (pure water, 5, 10, 25, 50 and $75 \%$ 2-propanol-water mixtures and pure 2-propanol). The sessile drop method was used with the same mixtures. Drops of $30 \mu$ l of liquid were deposited on the packed cocoa powder surface. No compression was exerted on the powder to avoid modification of the surface structure and composition of the cocoa particles. The static contact angles were determined as a function of the surface energy of the solutions. Then, the capillary rise method was adopted with pure water and pure 2-propanol into a packed powder bed of $1 \mathrm{~cm}$ height to determine the dynamic cocoa powder-water contact angle.

The surface energies and the contact angles were measured at $20^{\circ} \mathrm{C}$ with Krüss devices (K12 tensiometer and with a goniometer G40 connected to a Sony camera). Each measurement was repeated three times. The standard deviation for the contact angles measurements was $\pm 3^{\circ}$.

\section{Dispersion Kinetics}

The dispersion kinetic measurements of the cocoa powder were performed in a steel reactor equipped with a mechanical stirrer and with an optical fibre sensor (Figure 1). This technique allows the determination of the fluctuations of volume concentrations in a suspension, which can be interpreted in terms of the quality of the dispersion. The sensor is composed of a central emitting

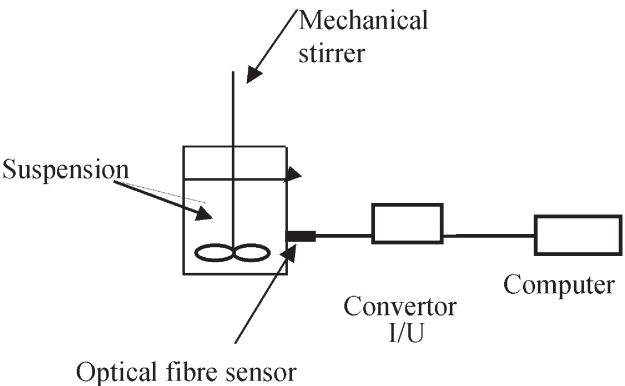

Figure 1. Experimental equipment.

optical fibre and a six-fibre crown to collect the light back-scattered by the particles in the suspension (Figure 2; see Bergougnoux et al., 1999 for more details).

First, a calibration curve of voltage $R$ vs the cocoa powder concentration $C$ was performed by dispersing a given amount of cocoa powder in water at high agitation speed over a long time to obtain a constant signal. Then, the voltage referring to the particle concentration $C \infty$ was considered as the infinite response $R \infty$. The relative concentration $X(t)$ of dispersed cocoa particles was determined as a function of time using equation (2):

$$
X(t)=\frac{R(t)}{R \infty}=\frac{C(t)}{C \infty}
$$

The experimental curves were fitted to the two-parameters exponential model of equation (3):

$$
X(t)=A[1-\exp (-\alpha t)]
$$

An example of dispersion kinetic is shown in Figure 3. Two experimental parameters were then deduced from this curve: $t_{(1 / 2) \mathrm{d}}(\mathrm{s})$, the half-time dispersion, and $t_{\mathrm{d}}(\mathrm{s})$, the dispersion time referred to the time at $X(t)=0.9$.

The initial dispersion rate was calculated for each experimental condition with the initial slope of the dispersion curve, and a very good correlation was observed with $\alpha\left(\mathrm{s}^{-1}\right)$. This parameter quantifies the dispersion rate of the particles. The other parameter $A$ corresponds to the final stage of the dispersion, close to 1 when all the particles are totally dispersed in the water. Other authors have used this exponential model to describe the dissolution kinetics of alginate powders (Larsen et al., 2003). They also gave the same interpretation of the two mathematical parameters.

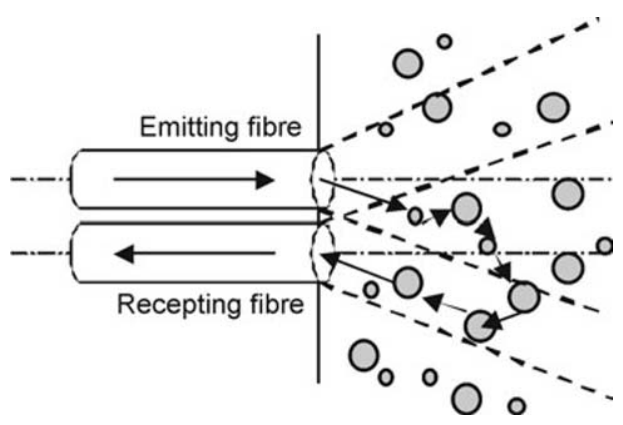

Figure 2. Principle of the optical fibres sensor. 


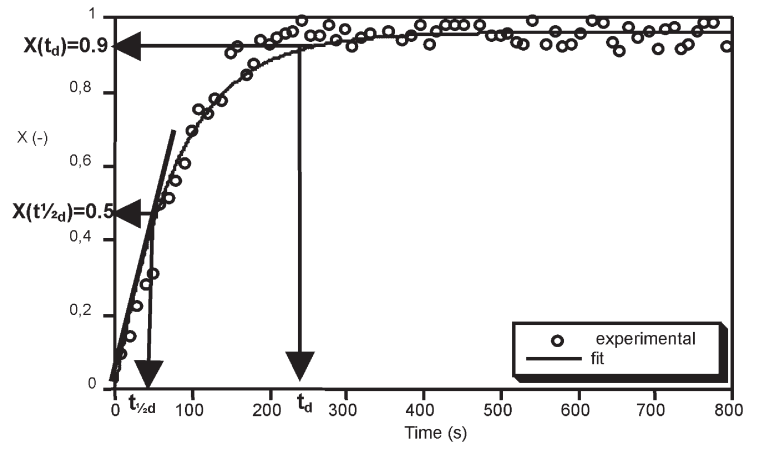

Figure 3. Experimental and fitted dispersion kinetic curves.

Preliminary studies have shown that the reactor geometry has little influence on the dispersion kinetics. The mechanical stirrer has more influence (shape, number of blades for example). In this study the steel reactor (length $16 \mathrm{~cm}$, width $16 \mathrm{~cm}$ and height $20 \mathrm{~cm}$ ) was fitted with a $6 \mathrm{~cm}$ diameter dispersion disc. The method to introduce the particles was also a critical parameter (there was faster dispersion when the cocoa particles were sprinkled, for example). In this study, cocoa powder $(10,20$ or $30 \mathrm{~g})$ was simply dropped in a mass on to the surface of the liquid (21).

\section{RESULTS AND DISCUSSION}

\section{Surface Free Energy and Contact Angles}

Using the sprinkling method, we observed that at high surface energy only few particles on the surface were wetted by the liquid. The cocoa powder was partially wetted when the surface energy of the liquid was less than $50 \mathrm{~mJ} \mathrm{~m}^{-2}$. When the surface energy of liquid was lower (between 30 and $40 \mathrm{~mJ} \mathrm{~m}^{-2}$ ), the cocoa particles were wetted and some particles went down slowly in the liquid. When the surface energy of the liquid was less than $30 \mathrm{~mJ} \mathrm{~m}^{-2}$, all the particles were rapidly wetted and sank in the liquid. The equivalent surface energy of cocoa powder was difficult to estimate using this method. We conclude that liquids with lower surface energies than $40 \mathrm{~mJ} \mathrm{~m}^{-2}$ will wet the cocoa powder.

The static contact angles $\theta$ as a function of $\gamma$ the surface energy of the water-2-propanol mixtures are given in Figure 4. The results confirm a step near $40 \mathrm{~mJ} \mathrm{~m}^{-2}$ : for surface energy lower than this value, the contact angle decreases as a function of the surface energy but for values greater than $40 \mathrm{~mJ} \mathrm{~m}^{-2}$, the contact angle is

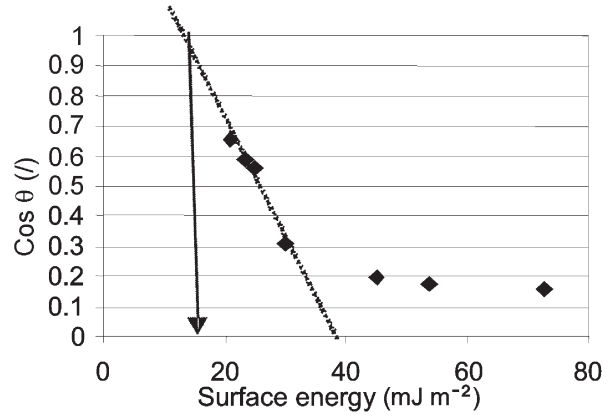

Figure 5. $\operatorname{Cos} \theta$ as a function of surface energy of liquids.

constant near $80^{\circ}$. The Zisman's plot ( $\cos \theta$ in function of $\gamma$ ) is shown in Figure 5. The extrapolation of the line [of equation $\cos \theta=1+\mathrm{b}\left(\gamma-\gamma_{\mathrm{c}}\right)$ ] permits $\gamma_{\mathrm{c}}$ to be determined, where $\gamma_{\mathrm{c}}$ is the limiting surface energy such that liquids with $\gamma<\gamma_{\mathrm{c}}$ will wet the solid with zero contact angle (Zisman, 1964). For cocoa powder, this limiting surface energy is $15 \mathrm{~mJ} \mathrm{~m}^{-2}$. Liquids with higher surface energies will not spread perfectly on the powder (nonzero contact angle). The curve shows the same inflection point between $30 \mathrm{~mJ} \mathrm{~m}^{-2}$ and $40 \mathrm{~mJ} \mathrm{~m}^{-2}$.

These two methods gave the minimum surface energy of the liquids that gave perfect wetting $\left(\gamma=15 \mathrm{~mJ} \mathrm{~m}^{-2}\right)$ or partial wetting $\left(\gamma=40 \mathrm{~mJ} \mathrm{~m}^{-2}\right)$ of the cocoa powder. Water, with a high surface energy $\left(72.8 \mathrm{~mJ} \mathrm{~m}^{-2}\right.$ at $\left.20^{\circ} \mathrm{C}\right)$ should be a very poor wetting liquid. We confirmed this with Washburn's capillary rise experiments. An ideal wetting liquid was not used due to the partial solubility of the cocoa powder in alkanes such as hexane. To determine the constant $K$, we used pure 2-propanol and the dynamic contact angle was assumed to be equal to the static contact angle determined above. This hypothesis is in accordance with Buckton's review, in which the comparison of the two contact angle measurement methods gave the same results for contact angle up to $70^{\circ}$ (Buckton, 1990).

The capillary rise into the cocoa powder bed was investigated with pure water, pure 2-propanol and mixtures of the two. The capillary rise took a time long even for the pure 2-propanol (about $30 \mathrm{~min}$ ) but the complete cocoa powder bed was wetted. The dynamic contact angles were calculated from the initial slope of the capillary rise kinetics and plotted as a function of the surface energy of the liquids in Figure 6. An important modification of the curve was observed near $30 \mathrm{~mJ} \mathrm{~m}^{-2}$. The very high

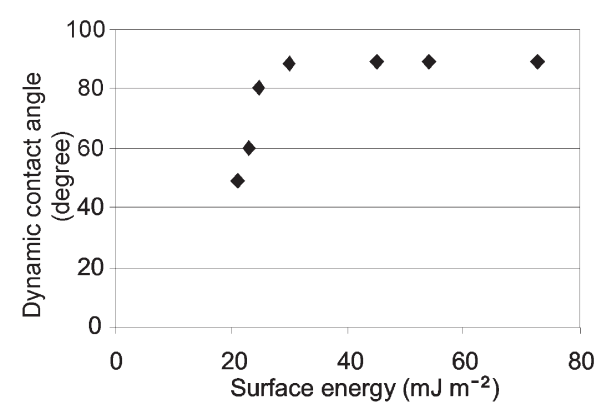

Figure 6. Dynamic contact angle as function of surface energy of liquids.

Figure 4. Static contact angle of drops on coca surface as a function of surface energy of liquids.

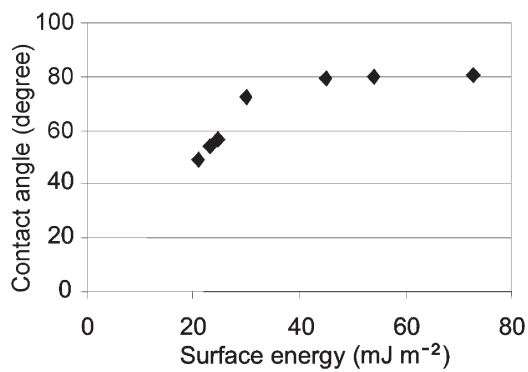


Table 2. Surface energy components and contact angles $\left(20^{\circ} \mathrm{C}\right)$.

\begin{tabular}{lcccc}
\hline & $\gamma\left(\mathrm{mJ} \mathrm{m}^{-2}\right)$ & $\gamma^{\mathrm{p}}\left(\mathrm{mJ} \mathrm{m}^{-2}\right)$ & $\gamma^{\mathrm{d}}\left(\mathrm{mJ} \mathrm{m}^{-2}\right)$ & $\theta\left(^{\circ}\right)$ \\
\hline Water & 72.8 & 51.0 & 21.8 & 89 \\
2-Propanol & 21.4 & 19.3 & 2.1 & 47 \\
Cocoa powder & 27.3 & 11.4 & 15.9 & - \\
\hline
\end{tabular}

values of the contact angles with water $\left(89^{\circ}\right)$ and mixtures with surface energies higher than $30 \mathrm{~mJ} \mathrm{~m}^{-2}$ revealed very poor wetting of these liquids. These measurements confirmed that water is a non-wetting liquid for cocoa powder. The dynamic contact angle measurements revealed a limiting surface energy to characterize the wettability of liquids on the cocoa powder; this limit was $30 \mathrm{~mJ} \mathrm{~m}^{-2}$.

Additional investigations were done to calculate surface energy of the cocoa powder. The polar $\gamma^{\mathrm{p}}$ and dispersive $\gamma^{\mathrm{d}}$ components of the surface energy of the two liquids, water and 2-propanol, were used to determine the surface energy of the cocoa powder using equation (4) (Wu and Kenneth, 1971):

$$
(1+\cos \theta) \gamma_{\mathrm{L}}=4\left(\frac{\gamma_{\mathrm{S}}^{\mathrm{p}} \cdot \gamma_{\mathrm{L}}^{\mathrm{p}}}{\gamma_{\mathrm{S}}^{\mathrm{p}}+\gamma_{\mathrm{L}}^{\mathrm{p}}}+\frac{\gamma_{\mathrm{S}}^{\mathrm{d}} \cdot \gamma_{\mathrm{L}}^{\mathrm{d}}}{\gamma_{\mathrm{S}}^{\mathrm{d}}+\gamma_{\mathrm{L}}^{\mathrm{d}}}\right)
$$

For water, the surface energy components are well known (Van Oss et al., 1989; Planinšek et al., 2000). For 2propanol, we used nearly the same $\gamma^{\mathrm{d}} / \gamma$ ratio (0.9) as for 1-propanol, with respect to a surface energy value of $21.4 \mathrm{~mJ} \mathrm{~m}^{-2}$ at $20^{\circ} \mathrm{C}$ (Chibowski, 2003; CRC Handbook, 2002). The contact angles were taken from the previous experiments: $89 \pm 3^{\circ}$ for water and $49 \pm 3^{\circ}$ for 2 propanol. We then had two equations with two unknown quantities $\gamma_{\mathrm{S}}^{\mathrm{p}}$ and $\gamma_{\mathrm{S}}^{\mathrm{d}}$ The double equation system was solved and the values used are reported in Table 2. The surface energy components $\gamma_{S}^{\mathrm{p}}$ and $\gamma_{\mathrm{S}}^{\mathrm{d}}$ for the cocoa powder were, respectively, 11.4 and $15.9 \mathrm{~mJ} \mathrm{~m}^{-2}$. The calculated surface energy of the cocoa powder was then $27.3 \mathrm{~mJ} \mathrm{~m}^{-2}$. This value was very close to $30 \mathrm{~mJ} \mathrm{~m}^{-2}$ and was in agreement with the limiting surface energy of liquids to wet the powder.

The solid-surface free energy components of cocoa powder were used to calculate the spreading coefficients, $\lambda$, to predict the interactions with water. The intermediate parameters ( $W_{\text {coh }}$, work of cohesion, and $W_{\mathrm{SL}}$, work of adhesion) were calculated from equation (5). The two spreading coefficients, $\lambda_{\mathrm{SL}}$ and $\lambda_{\mathrm{LS}}$, calculated from equation (6), are given in Table 3 . For more details see Hie-

Table 3. Cocoa powder-water interaction parameters $\left(20^{\circ} \mathrm{C}\right)$.

\begin{tabular}{lcccccc}
\hline & $\begin{array}{c}\gamma \\
\left(\mathrm{mJ} \mathrm{m}^{-2}\right)\end{array}$ & $\begin{array}{c}W_{\mathrm{coh}} \\
\left(\mathrm{mJ} \mathrm{m}^{-2}\right)\end{array}$ & $\begin{array}{c}W_{\mathrm{SL}} \\
\left(\mathrm{mJ} \mathrm{m}^{-2}\right)\end{array}$ & $\begin{array}{c}\theta \\
\left({ }^{\circ}\right)\end{array}$ & $\begin{array}{c}\lambda_{\mathrm{SL}} \\
\left(\mathrm{mJ} \mathrm{m}^{-2}\right)\end{array}$ & $\begin{array}{c}\lambda_{\mathrm{LS}} \\
\left(\mathrm{mJ} \mathrm{m}^{-2}\right)\end{array}$ \\
\hline $\begin{array}{l}\text { Water } \\
\begin{array}{c}\text { Cocoa } \\
\text { powder }\end{array}\end{array}$ & 27.8 & 145.6 & - & - & - & - \\
$\begin{array}{c}\text { Interaction } \\
\text { parameter }\end{array}$ & - & 54.6 & - & - & - & - \\
\hline
\end{tabular}

Table 4. Half-times and dispersion times of cocoa powder in water as function of agitation speed.

\begin{tabular}{|c|c|c|c|c|c|c|c|}
\hline & \multirow[b]{2}{*}{$C(\%)$} & \multicolumn{3}{|c|}{$t_{1 / 2 \mathrm{~d}}(\mathrm{~s})$} & \multicolumn{3}{|c|}{$t_{\mathrm{d}}(\mathrm{s})$} \\
\hline & & 0.5 & 1.0 & 1.5 & 0.5 & 1.0 & 1.5 \\
\hline \multirow{5}{*}{$\begin{array}{c}\text { Agitation } \\
\text { speed }\end{array}$} & $240 \mathrm{rpm}$ & 143 & 195 & 359 & - & - & - \\
\hline & $450 \mathrm{rpm}$ & 47 & 77 & 168 & 80 & 450 & 650 \\
\hline & $630 \mathrm{rpm}$ & 34 & 30 & 57 & 40 & 150 & 200 \\
\hline & $820 \mathrm{rpm}$ & 15 & 13 & 15 & 22 & 100 & 80 \\
\hline & $1100 \mathrm{rpm}$ & 6 & 9 & 8 & 6 & 45 & 30 \\
\hline
\end{tabular}

menz (1997), Rowe (1989a) and Planinšek et al. (2000).

$$
\begin{aligned}
& W_{\mathrm{coh}}=2 . \gamma \quad W_{\mathrm{SL}}=(1+\cos \theta) \cdot \gamma_{\mathrm{L}} \\
& \lambda_{\mathrm{SL}}=W_{\mathrm{SL}}-W_{\mathrm{cohL}} \quad \lambda_{\mathrm{LS}}=W_{\mathrm{SL}}-W_{\mathrm{cohS}}
\end{aligned}
$$

In accordance with Rowe (1989b), the above spreading coefficients reveal a non-spreading behaviour of water on the cocoa particles, with the formation of liquid bridges between the particles. This conclusion confirms the lack of affinity of water for cocoa powder.

\section{Influence of Agitation Speed on Dispersion Kinetics}

The influence of the agitation speed on the dispersion kinetic of the cocoa powder in pure water was studied for three concentrations $(0.5,1$ and $1.5 \%$ in mass fraction), at $20^{\circ} \mathrm{C}$. The parameters calculated from the curves are given in Tables 4 and 5. The fitted curves for concentration $1.5 \%$ are shown in Figure 7.

Without agitation the cocoa powder stayed at the surface of the water for a long time without being wetted and dispersed (Figure 7). This is in agreement with the nonwetting properties of liquids with high surface energy and our previous observations concerning the capillary rise experiments. At low agitation speed $(240 \mathrm{rpm})$, the dispersion of the cocoa particles was not complete $\left(t_{\mathrm{d}}\right.$ cannot be deducted) and $A$ was very much less than 1 . We observed some cocoa particles remaining at the surface. At higher agitation speed, we observed that the dispersion was total for all cocoa concentrations. All the cocoa particles were removed from the surface and were swept along by the vortex. The concentration of dispersed particles in water increased more rapidly when the agitation speed increased. The dispersion time $t_{\mathrm{d}}$ decreased with agitation speed and at the same speed increased with the cocoa powder concentration. The analysis of the results

Table 5. Mathematical parameters $\alpha$ and $A$ as function of agitation speed.

\begin{tabular}{ccccccccc}
\hline & & \multicolumn{3}{c}{$\alpha\left(\mathrm{s}^{-1}\right)$} & & \multicolumn{3}{c}{$A$} \\
\cline { 3 - 5 } \cline { 7 - 9 } & $C(\%)$ & 0.5 & 1.0 & 1.5 & & 0.5 & 1.0 & 1.5 \\
\hline $\begin{array}{c}\text { Agitation } \\
\text { speed }\end{array}$ & $240 \mathrm{rpm}$ & 0.007 & 0.006 & 0.003 & 0.789 & 0.695 & 0.721 \\
& & & & & & & \\
& $450 \mathrm{rpm}$ & 0.015 & 0.010 & 0.005 & 0.974 & 0.924 & 0.910 \\
& $630 \mathrm{rpm}$ & 0.023 & 0.025 & 0.013 & 0.902 & 0.935 & 0.961 \\
& $820 \mathrm{rpm}$ & 0.051 & 0.056 & 0.050 & 0.925 & 1.000 & 0.967 \\
& $1100 \mathrm{rpm}$ & 0.125 & 0.084 & 0.070 & 0.925 & 0.977 & 1.000
\end{tabular}




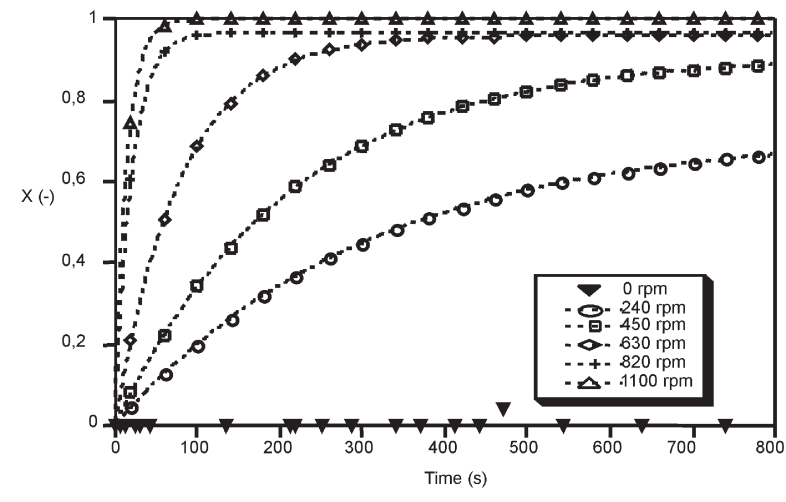

Figure 7. Dispersion kinetic curves of cocoa powder as function of agitation speed, concentration $1.5 \%$.

also revealed that for the three concentrations the dispersion kinetics were not very different at high agitation speeds. Under our experimental conditions the limiting speed was $630 \mathrm{rpm}$. This was well demonstrated at 1 and $1.5 \%$ concentrations: when the agitation speed was greater than $630 \mathrm{rpm}$, there was no further improvement in the dispersion kinetics.

These results confirm that the mechanical agitation is necessary to disperse the cocoa particles. This can be related to the high particle-particle interactions and poor spreading properties of water. Mechanical energy is necessary to break the particle aggregates and create the cocoawater interface to disperse the particles, but, beyond a limit, there is no further improvement in the dispersion rate.

\section{Influence of Temperature on Dispersion Kinetics}

The dispersion kinetics of the cocoa powder were measured at different temperatures from 20 to $35^{\circ} \mathrm{C}$, at $1 \%$ and $630 \mathrm{rpm}$. The dispersion data are shown in Figure 8. The two parameters $A$ and $\alpha$ are reported in Table 6.

We observed that the temperature had a large effect on the dispersion kinetics of the cocoa powder. An increase in temperature improved the dispersion of the cocoa particles in water. This can be explained by the modification of the physical properties of water covering viscosity and, in particular, surface energy. A decrease in the surface

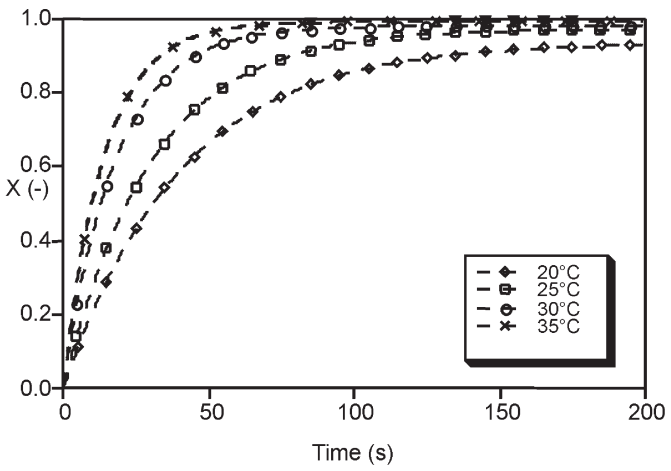

Figure 8. Dispersion kinetic curves of cocoa powder as function of temperature, concentration $1 \%$.
Table 6. Mathematical parameters $\alpha$ and $A$ as function of temperature.

\begin{tabular}{lcc}
\hline$T\left({ }^{\circ} \mathrm{C}\right)$ & $\alpha\left(\mathrm{s}^{-1}\right)$ & $A$ \\
\hline 20 & 0.025 & 0.93 \\
25 & 0.033 & 0.97 \\
30 & 0.055 & 0.98 \\
35 & 0.070 & 0.99 \\
\hline
\end{tabular}

energy of the water enhanced dispersion by decreasing the work of cohesion of the liquid. Thus, higher temperature also favour the dispersion of cocoa powder in water.

\section{CONCLUSIONS}

This experimental work brings some new considerations into the dispersion kinetics of a powder in water. Cocoa powder is a good example for this study due to its end-use (e.g. in instant powder) and because of its high cohesivity. The study of the solid-liquid interactions reveals very poor wettability of cocoa powder in water. The surface energy of the cocoa powder has been estimated to be around $30 \mathrm{~mJ} \mathrm{~m}^{-2}\left(27.3 \mathrm{~mJ} \mathrm{~m}^{-2}\right)$. The spreading coefficient values are in accordance with a non-energetically favourable water spreading on the cocoa particles.

We have then investigated the dispersion kinetics of cocoa powder in water. The optical method used is very accurate for measuring the concentration of solid particles in liquids as a function of time. All experimental data fit an exponential equation with two parameters. These parameters are highly dependent on the experimental conditions. The interpretation of the results reveals that both mechanical agitation and the temperature are critical parameters. Mechanical agitation enhances dispersion kinetics by forcing the creation of a water-cocoa interface, and the temperature acts to decrease the work of cohesion of water.

\section{NOMENCLATURE}

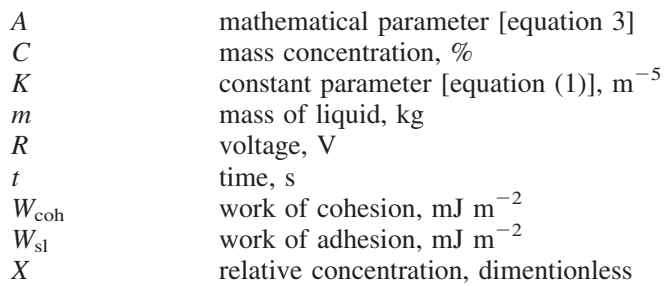

$\begin{array}{ll}\text { Greek symbols } & \\ \alpha & \text { mathematical parameter [equation (3)], s } \\ \gamma & \text { surface energy, } \mathrm{mJ} \mathrm{m}^{-2} \\ \eta & \text { viscosity, Pa s } \\ \lambda & \text { spreading coefficient, } \mathrm{mJ} \mathrm{m}^{-2} \\ \theta & \text { contact angle, } \mathrm{deg} \\ \rho & \text { liquid density, } \mathrm{kg} \mathrm{m}^{-3}\end{array}$




\section{REFERENCES}

Bergougnoux, L., Firpo, J.L. and Misguish-Ripault J., 1999, Optical fiber sensor for measuring high particles concentrations, Powder Technol, 105: 413-417.

Buckton, G., 1990, Contact angle adsorption and wettability-a Review with respect to powders, Powder Technol, 61: 237-249.

Chibowski, E., 2003, Surface free energy of a solid from contact angle hysteresis, Adv Colloid Interface Sci, 103: 149-172.

CRC Handbook, 2002, Surface tension of common liquids, in CRC Handbook of Chemistry and Physics: a Ready-reference Book of Chemical and Physical Data, 83rd edn (CRC Press, Boca Raton, FL, USA), pp 6-136.

Good, R.J., 1977, Surface free energy of solids and liquids: thermodynamics, molecular forces and structure, Colloid Interface Sci, 59: $398-419$.

Hiemenz, P.C., 1997, Principles of Colloid and Surface Chemistry, 3rd edn (Wiley, Chichester, UK).

Kyaw Hla, P. and Hogekamp, S., 1999, Wetting behaviour of instantized cocoa beverage powders, Int J Food Sci Technol, 34: 335-342.

Larsen, C.K., Gåserød, O. and Smidsrød, O., 2003, A novel method for measuring hydration and dissolution kinetics of alginate powders, Carbohydr Polym, 51: 125-134.

Planinšek, O., Pišek, R., Trojak, A. and Srčič, S., 2000, The utilization of surface free-energy parameters for the selection of a suitable binder in fluidized bed granulation, Int J Pharm, 207: 77-88.

Rowe, R.C., 1989a, Binder-substrate interactions in granulation: a theoretical approach based on surface free energy and polarity, Int J Pharm, 52: 149-154.
Rowe, R.C., 1989b, Surface free energy and polarity effects in the granulation of a model system, Int J Pharm, 53: 75-78.

Schubert, H., 1993, Instantization of powdered food products, Int Chem Eng, 33, 1: 28-45.

Stevens, P., Gypen, L. and Jennen-Bartholomeussen, R., 1974, Wettability of powders, Farmaceutish Tijdschrift Voor Belgie, 51: 150-155.

Van Oss, C.J., Ju, L., Chaudhury, M.K. and Good, R.J., 1989, Estimation of the polar parameters of the surface tension of liquids by contact angle measurements on gels, J Colloid Interface Sci, 128: 313-319.

Vu, T., Galet, L., Fages, J. and Oulahna, D., 2003, Improving the dispersion kinetics of a cocoa powder by size enlargement, Powder Technol, 130: 400-406.

Wu, S. and Kenneth, J.B., 1971, Surface free energy and polarity of organic pigments, J Colloid Interface Sci, 37: 686-690.

Yang, Y.-W., Zografi, G. and Miller, E., 1988, Capillary flow, phenomena and wettability in porous media, II. Dynamic flow studies, $J$ Colloid Interface Sci, 122: 35-46.

Zisman, W.A., 1964, Relation of the equilibrium contact angle to liquid and solid constitution, Adv Chem Ser, 4: 1-51.

\section{ACKNOWLEDGEMENTS}

The authors are grateful to Phoscao (Chateauneuf/Loire, France) for providing the cocoa powder and to L. Bergougnoux and to MisguishRipault J. for their assistance in performing the optical device. 